\title{
Rare Isolated Renal Involvement with Marginal Zone B Cell Lymphoma: A Case Report with Literature Review of Contemporary Management Strategies
}

\author{
Muhammad J. Khalil ${ }^{1}$, Mustafa N. Malik ${ }^{1}$, Maryam Ahmed ${ }^{1}$, Abdul Rafae ${ }^{1}$, Faiz Anwer ${ }^{1}$ \\ 1. Hematology and Oncology, The University of Arizona, Tucson, USA
}

Corresponding author: Mustafa N. Malik, mustafa.nadeem.malik@gmail.com

\begin{abstract}
Marginal zone B cell lymphomas are divided into nodal, extranodal and splenic types. Renal involvement by extranodal B cell lymphoma is extremely rare with an incidence of about $0.1 \%$. We present a case of a 79 year-old Caucasian male with progressive renal failure and isolated left renal extranodal marginal zone lymphoma. Asymptomatic immunoglobulin (Ig) M monoclonal gammopathy along with bone marrow involvement by lymphoma was observed. Contemporary management options including radiotherapy (RT), chemotherapy, immune-modulating agents and novel chemotherapy-free regimens.
\end{abstract}

Categories: Oncology

Keywords: marginal zone b-cell lymphoma, chemotherapy, renal insufficiency

\section{Introduction}

Marginal zone lymphomas (MZL) are low-grade non-Hodgkin B cell lymphomas (NHL) classified into three subcategories such as extranodal marginal zone lymphoma (EMZL), also called mucosal-associated lymphoid tissue (MALT) lymphoma, nodal marginal zone lymphoma (NMZL) and splenic marginal zone lymphoma (SMZL). EMZLs account for $8 \%$ of all NHL cases [1]. Most commonly, the EMZLs are found in the stomach, followed by spleen, eye, adnexa, lungs, skin, salivary glands, thyroid, small intestine, breast, synovium, dura and soft tissues. As kidneys lack the lymphoid tissues, renal involvement with EMZLs is extremely rare. Only a handful of such cases have been reported [2]. B cell lymphomas also present with paraproteinemia [3]. We report a case of a Caucasian male who presented with a progressive decline in renal function associated with isolated left renal involvement with marginal zone B cell lymphoma and asymptomatic immunoglobulin (Ig) M monoclonal gammopathy. Moreover, we reviewed the contemporary management options for MZLs.

Received 08/14/2018 Review began 11/01/2018 Review ended 11/05/2018 Published 11/08/2018

() Copyright 2018 Khalil et al. This is an open access article distributed under the terms of the Creative Commons Attribution License CC-BY 3.0., which permits unrestricted use, distribution, and reproduction in any medium, provided the original author and source are credited.

\section{Case Presentation}

A 79-year-old asymptomatic Caucasian male presented with progressive renal failure with abnormal serum creatinine (range of 1.82 to 2.18 ) in July 2012. Complete blood count (CBC) showed red blood cell count (RBC) of 3.36 x 108/uL, hemoglobin $10.9 \mathrm{~g} / \mathrm{dl}$, hematocrit 33.1\%, mean corpuscular volume (MCV) $99 \mathrm{fL}$, mean corpuscular hemoglobin (MCH) 32.8 pg, mean corpuscular hemoglobin concentration (MCHC) 33.0\%, red cell distribution width (RDW) $15.8 \%$ and white blood cell count (WBC) 4,000/uL, with differentials: neutrophils $50 \%$, lymphocytes $37 \%$, monocytes $8 \%$, eosinophils $4 \%$, basophils $1 \%$ and platelet count of 178,000/uL. Comprehensive metabolic profile (CMP) revealed: glucose $96 \mathrm{mg} / \mathrm{dL}$, blood urea nitrogen 23 $\mathrm{mg} / \mathrm{dL}$, creatinine $2.18 \mathrm{mg} / \mathrm{dL}$, sodium $140 \mathrm{mmol} / \mathrm{L}$, potassium $4 \mathrm{mmol} / \mathrm{L}$, chloride $107 \mathrm{mmol} / \mathrm{L}$, carbon dioxide $25 \mathrm{mmol} / \mathrm{L}$, albumin $4.4 \mathrm{~g} / \mathrm{dL}$, calcium $9.1 \mathrm{mg} / \mathrm{dL}$, bilirubin (total) $0.8 \mathrm{mg} / \mathrm{dL}$, phosphorus 3.3 $\mathrm{mg} / \mathrm{dL}$ and magnesium $2.7 \mathrm{mg} / \mathrm{dL}$. Computed tomography (CT)-guided needle biopsy of the left kidney showed severe lymphocytic inflammation mainly in the areas of tubular atrophy and interstitial fibrosis (Figure 1). 


\section{Cureus}

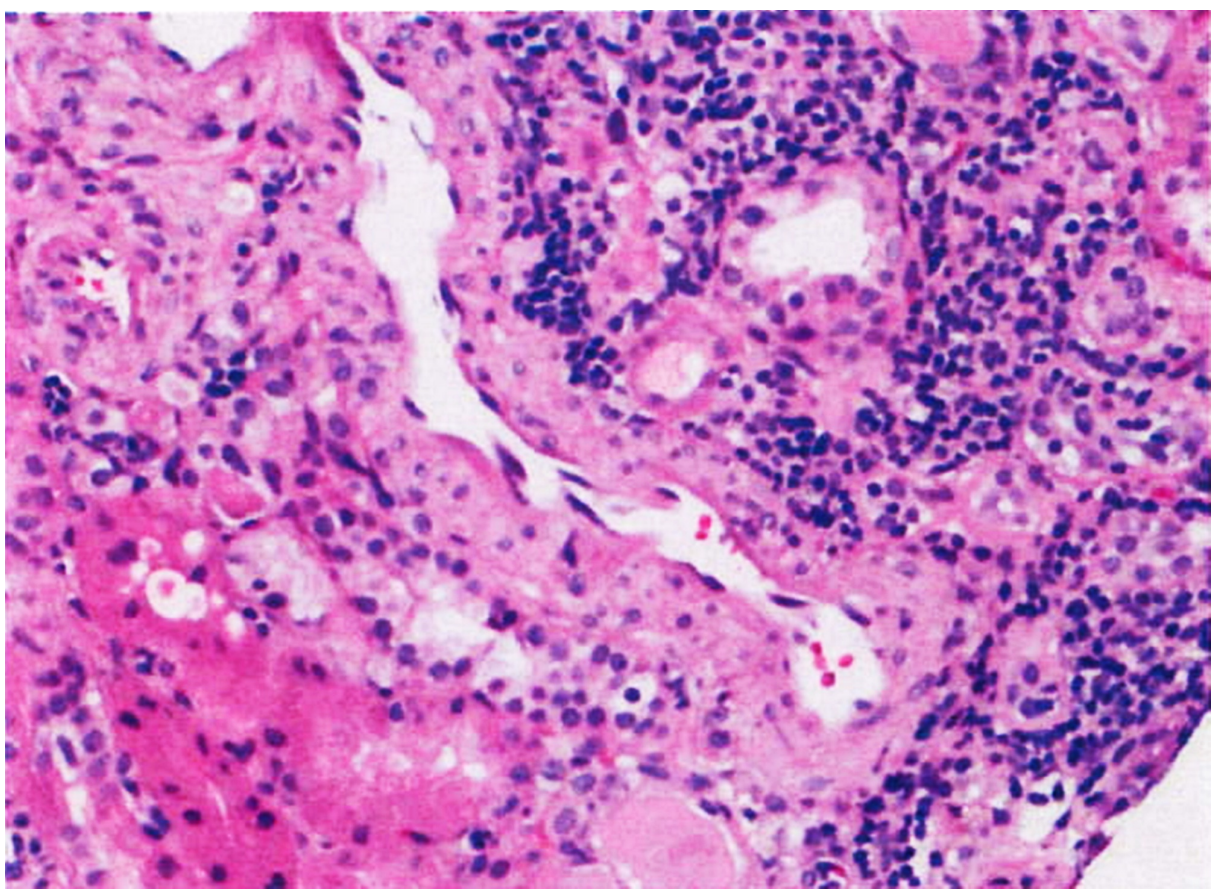

FIGURE 1: Interstitial inflammation with lymphocytes

Immunohistochemical staining showed atypical lymphocytes that were positive for $\mathrm{CD} 20$ and negative for $\mathrm{CD} 5, \mathrm{CD} 10, \mathrm{CD} 19, \mathrm{CD} 22$ and $\mathrm{CD} 23$. Molecular testing revealed an Ig heavy chain gene rearrangement; these findings were consistent with marginal zone B cell lymphoma. Furthermore, immunofluorescence (IF) microscopy demonstrated seven glomeruli with diffuse pseudo-linear staining of the glomerular capillary loops for albumin (1+). Glomerular staining for IgG, IgA, IgM, C3, C1q and kappa or lambda light chain was negative. Interstitium stained positive for fibrinogen, while protein casts were stained positive for IgA (3+), kappa light chain (3+) and lambda light chain (3+). By electron microscopy (EM), the glomerular basement membrane had a normal trilaminar structure, the mean thickness was within the normal range without electron-dense deposits or tubuloreticular inclusions and the majority of podocytes foot processes were intact (Figure 2). No immune complexes were detected by IF or EM.

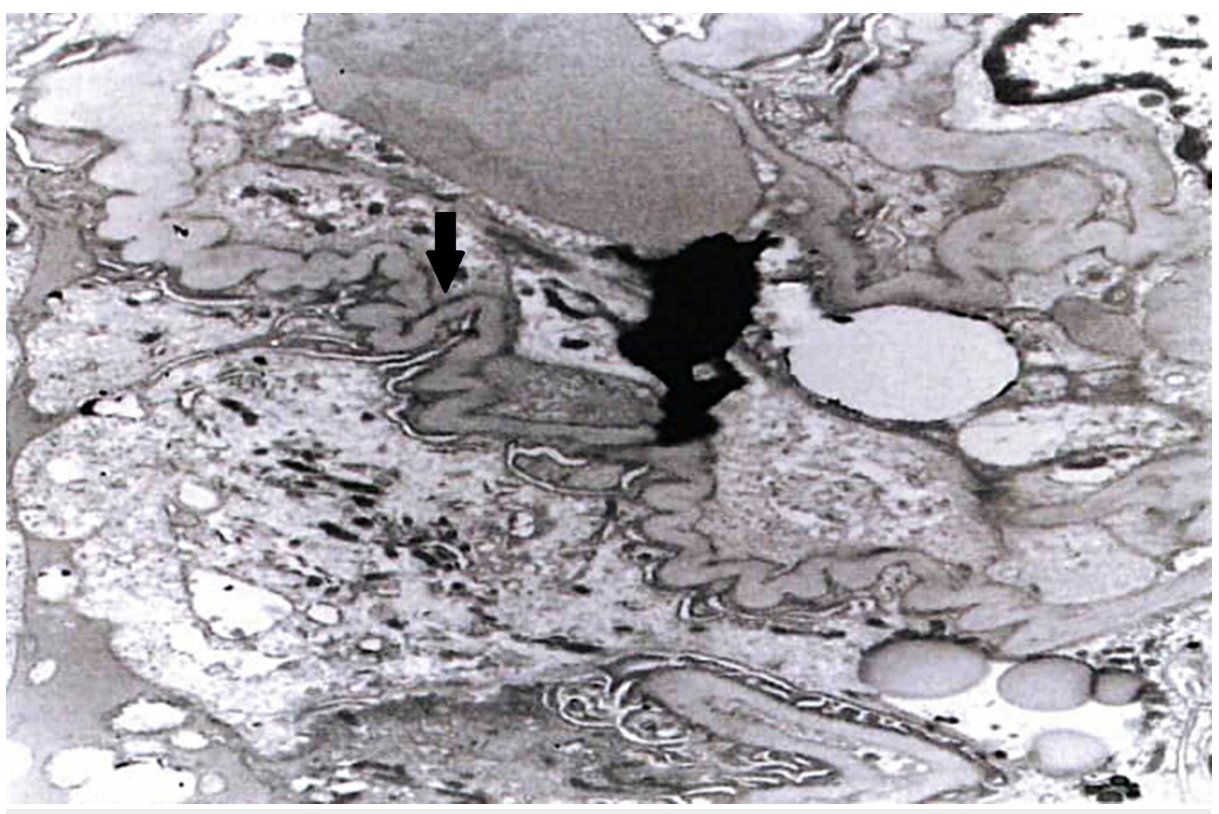

FIGURE 2: Wrinkling and folding of glomerular capillary loops

On serum protein electrophoresis (SPEP) and immunofixation, we found IgM kappa monoclonal gammopathy and serum M-protein level of $0.3 \mathrm{~g} / \mathrm{dL}$. Quantitative immunoglobulin testing was performed 
for IgG (699 mg/dL), IgA (51 mg/dL) and IgM (470 mg/dL). Serum free light chain (SFLC) showed kappa (37.9 $\mathrm{mg} / \mathrm{L})$, lambda (1.58 mg/L) and kappa/lambda ratio of 23.99. Urine protein electrophoresis (UPEP) showed a protein level of $91 \mathrm{mg} / \mathrm{dL}$ and M-spike of $18.1 \%$. Bone marrow (BM) biopsy showed 30\% BM involvement by clonal B cells, morphologically consistent with marginal zone B cell lymphoma. Positron emission tomography (PET) scan was found normal in 2012 and 2013. The patient was treated with five doses of weekly rituximab and one dose of rituximab-bendamustine combination, but renal function worsened and treatment was stopped in 2013. The patient was monitored closely without further treatment until 2017. PET scan (2017) showed a mild enlargement of the retroperitoneal lymph nodes (aortocaval from $1 \times 0.8$ to $1.4 \mathrm{x}$ $1.2 \mathrm{~cm}$, left periaortic from $1.4 \times 0.5$ to $1.3 \times 1.0 \mathrm{~cm}$ ) and a partially calcified subcarinal node from $3.1 \times 1.1$ to $3.5 \times 1.5 \mathrm{~cm}$ (non-avid), and the spleen size increased from 12.2 to $14.2 \mathrm{~cm}$ in cubic centimeter dimension (Figure 3). One dose of vincristine and prednisone was given at that time, but renal function declined further. The patient was offered bortezomib/dexamethasone or ibrutinib for further treatment consideration, which he declined.

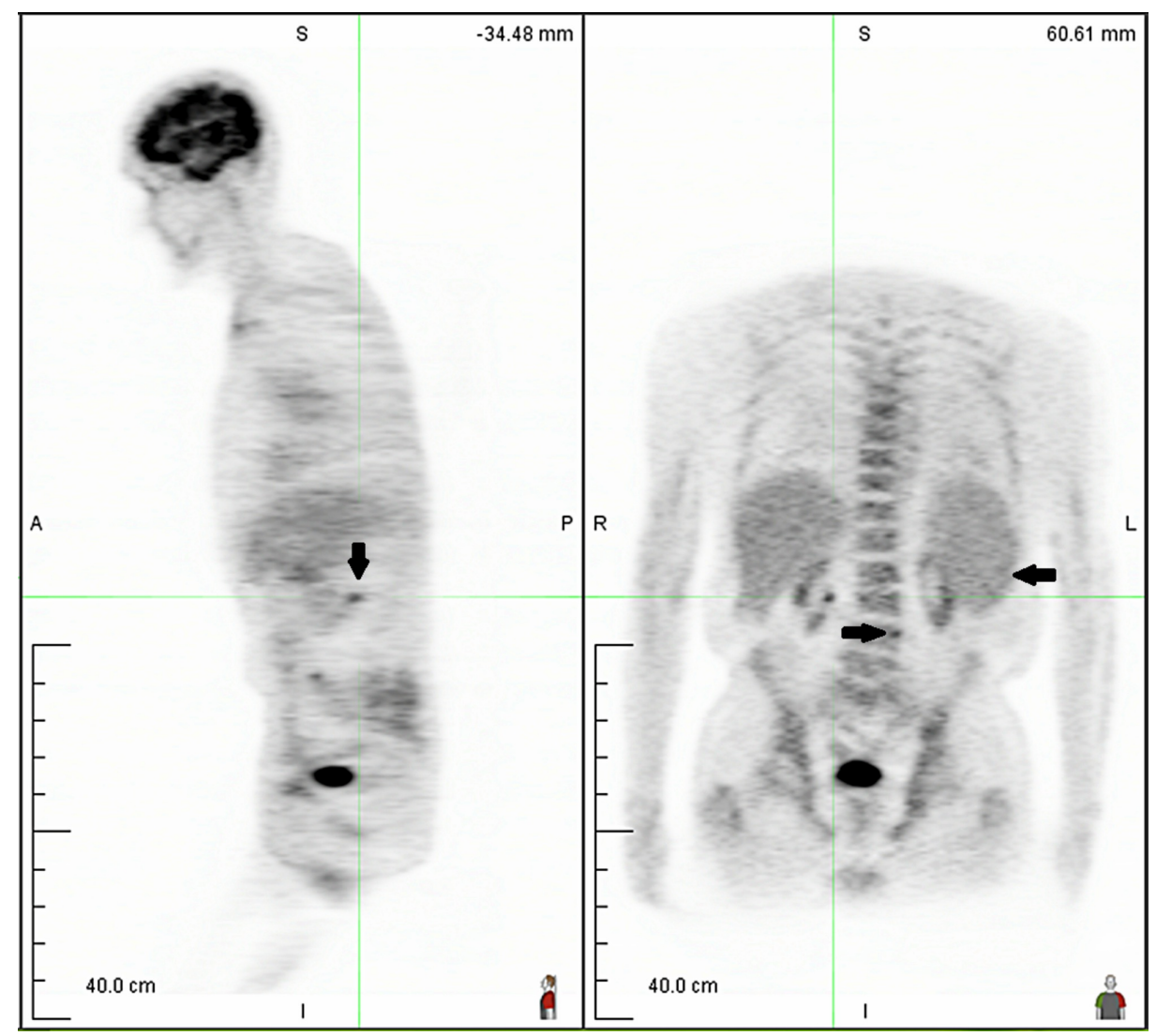

FIGURE 3: PET scan showing mild enlargement of retroperitoneal lymph nodes

PET: positron emission tomography

\section{Discussion}

Renal infiltration by lymphoma is rare, and such cases are often clinically silent [2]. EMZLs are more common than NMZLs or SMZLs and are subdivided into gastric and non-gastric types. The gastric EMZLs are caused by sustained inflammation with bacterial infection (Helicobacter pylori). Etiologies for non-gastric EMZLs include Borrelia burgdorferi infection in cutaneous EMZLs, Chlamydophila psittaci infection in ocular EMZLs and Campylobacter jejuni infection in small intestinal EMZLs. A higher prevalence of hepatitis $\mathrm{C}$ virus (HCV) infection has also been reported in patients with MZLs, particularly of the splenic and nodal types, suggesting a possible causative role of the HCV in MZLs [1].

As no lymphatic tissues are present in the renal parenchyma, the theories about the renal involvement with lymphoma suggest that either the lymphocytes migrate from the lymphatics in the renal capsule or the presence of chronic inflammation provides a platform for long-standing antigenic stimulation, thereby attracting the lymphoid cells and developing into a lymphoma. Mostly, the MZLs present as Ann-Arbor stage IE disease, and BM and peripheral lymph node involvement are rather uncommon. BM involvement has been reported in up to $20 \%$ of cases of MZLs [3]. 
EMZLs are indolent and have a tendency to remain localized to the site of origin for an extended period of time. It has the potential for a systematic spread and can transform to an aggressive B cell lymphoma. Histological transformation to large B cell lymphoma has been reported in approximately $10 \%$ of the cases [3]. Patients with EMZL have a relatively good prognosis with a median survival $>10$ years. Our patient had an indolent clinical behavior of MZL but was diagnosed with isolated left renal involvement at the time of diagnosis.

Treatment options depend on the site of organ involvement. For gastric EMZLs, options include H. pylori eradication therapy, radiotherapy (RT), chemotherapy and immune-modulating agents. For early-stage $H$. pylori-positive EMZL, H. pylori eradication therapy is recommended, followed by endoscopic surveillance. For advanced-stage $H$. pylori-positive gastric EMZL, treatment with $H$. pylori eradication therapy is recommended, followed by observation until the development of symptoms at which time chemotherapy is initiated. Initial treatment with local RT is recommended in patients with early-stage $H$. pylori-negative gastric EMZL.

Non-gastric EMZLs treatment depends on the organ involved and the stage of the disease. Limited-stage EMZL is generally treated with locoregional RT or managed expectantly. Surgery is typically used for diagnostic purposes only but may play a role in the treatment of tumors in areas not conducive to RT (e.g. localized lesion in the lung). Single-agent rituximab is an alternative for the treatment of sites that cannot be treated with RT. Advanced-stage diseases are treated with rituximab or combination chemotherapy. Chemotherapy or chemoimmunotherapy is given to newly diagnosed patients who show no response to single-agent rituximab or have disease relapse.

Rituximab, in combination with bendamustine, demonstrated an overall response rate (ORR) of $84 \%$, with a six-year progression-free survival (PFS) of $54 \%$ and an overall survival (OS) of $72 \%$ for newly diagnosed cases. For relapsed/ refractory MZL, bendamustine as a single agent was effective with an ORR of $76 \%$, and the median duration of response was 10 months [4]. Other chemotherapy combinations include rituximab/cyclophosphamide/vincristine/ prednisone (R-CVP), rituximab/fludarabine (FR) and fludarabine/cyclophosphamide/rituximab (FCR). These regimens have shown excellent efficacy with an ORR of $88 \%, 83 \%$ and $78.3 \%$, respectively [5-6].

Obinutuzumab, an anti-CD20 antibody, acts by inducing direct cell death and showed enhanced antibodydependent cell-mediated cytotoxicity (ADCC). In combination with bendamustine, it has shown a statistically significant ( $p=0.0001$; $95 \%$ confidence interval $(\mathrm{CI})=0.40-0.74$ ) increase in PFS over singleagent bendamustine (22.5 months vs. 14.9 months at two years) in 396 patients with indolent lymphomas that were resistant to rituximab (hazard ratio $=0.55$ ) [7].

Ibrutinib, a Bruton's tyrosine kinase inhibitor, is the first oral therapy approved by the Food and Drug Administration (FDA) for the management of relapsed/refractory (R/R) marginal zone lymphoma. It acts by inhibition of the B cell receptor (BCR) signaling pathway, an important pathway responsible for lymphoma genesis. A phase II study included 63 patients having R/R MZLs treated with ibrutinib. About 50\% of the patients had EMZL, and about a quarter patients had SMZL. Ibrutinib has shown excellent efficacy in these patients with an ORR of $48 \%$ and median PFS of 14.2 months [8].

Bortezomib, a proteasome inhibitor, has shown a significant single-agent activity in R/R MZLs with ORR of $48 \%$ [9]. In a randomized clinical trial involving 81 patients with R/R MZL, bortezomib in combination with rituximab was administered. The patients were randomly assigned into two groups with bortezomib (1.3 $\left.\mathrm{mg} / \mathrm{m}^{2}\right)$ twice weekly in group A and bortezomib $\left(1.6 \mathrm{mg} / \mathrm{m}^{2}\right)$ once weekly in group B. Both groups also received rituximab $\left(375 \mathrm{mg} / \mathrm{m}^{2}\right)$ weekly for 4 weeks. Group A showed an ORR of $49 \%$, while group B showed an ORR of $43 \%$ [10].

Rituximab, when used in combination with lenalidomide, has shown excellent efficacy with an ORR up to 80\% [11]. Other novel agents with activity against MZLs include high-dose cytarabine (HiDAC) inhibitors, phosphoinositide 3 kinase (PI3K) inhibitors and mammalian target of rapamycin (mTOR) inhibitors. These agents are currently in various phases of clinical trials (Table 1) [12-19]. One clinical trial involving 81 patients with relapsed B cell malignancies including MZL, wherein a novel chemotherapy-free triple regimen including umbralisib (PI3K $\Delta$ inhibitor), ibrutinib (Bruton's tyrosine kinase inhibitor) and ublituximab (glycoengineered anti-CD20 antibody) was used, showed an ORR of $86 \%$ [20]. 


\section{Cureus}

\begin{tabular}{|c|c|c|c|c|c|c|c|}
\hline Agent & Mode of Action & Disease & Phase & Patients & Dose (mg) & Route & Ref \\
\hline Venetoclax & Proto-oncogene protein c-bcl-2-inhibitors & $R / R$ & II & 138 & $50-800$ & PO & [14] \\
\hline Copanlisib & Phosphatidylinositol 3 kinase alpha inhibitors & $\mathrm{R} / \mathrm{R}$ & II & 56 & 60 & IV & [12] \\
\hline Buparlisib & Phosphatidylinositol 3 kinase inhibitors & $R / R$ & I & 18 & N.S & PO & [15] \\
\hline Duvelisib & Phosphatidylinositol 3 kinase delta inhibitors & $\mathrm{R} / \mathrm{R}$ & III & 600 & 200 & $\mathrm{PO}$ & [16] \\
\hline Vorinostat & Histone deacetylase inhibitors & $R / R$ & $\|$ & 37 & N.S & PO & [19] \\
\hline Idelalisib & Phosphatidylinositol 3 kinase delta inhibitors & $\mathrm{R} / \mathrm{R}$ & II & 125 & 150 & $\mathrm{PO}$ & [13] \\
\hline Lenalidomide & Immunomodulator & $\mathrm{R} / \mathrm{R}$ & II & 56 & $15-20$ & PO & [17] \\
\hline Umbralisib & Phosphatidylinositol 3 kinase delta inhibitors & $R / R$ & II & 40 & N.S & PO & [18] \\
\hline
\end{tabular}

TABLE 1: Drugs in various phases of development in clinical trials for the treatment of nonHodgkin B cell lymphoma

bcl: B cell lymphoma; IV: intravenous; N.S: not specified; PO: per oral; R/R: relapsed/refractory

Ibrutinib is being investigated in combination with lenalidomide +/- rituximab (clinicaltrials.gov, NCT02532257 and NCT01955499), selinexor (KPT-330), a selective inhibitor of nuclear export (clinicaltrials.gov, NCT02303392), and pembrolizumab, a checkpoint inhibitor (clinicaltrials.gov, NCT02332980) in R/R MZL and other B cell malignancies.

\section{Conclusions}

We report a case of marginal zone B cell lymphoma with isolated left renal involvement in a patient with progressive renal failure and asymptomatic IgM monoclonal gammopathy. MZLs are currently being treated with RT, chemotherapy and chemoimmunotherapy. Recently, chemotherapy-free regimens and other novel agents have gained importance. These agents are currently under development in various phases of clinical trials and may play an important role in the future management of MZLs and other B cell malignancies.

\section{Additional Information \\ Disclosures}

Human subjects: Consent was obtained by all participants in this study. Conflicts of interest: In compliance with the ICMJE uniform disclosure form, all authors declare the following: Payment/services info: All authors have declared that no financial support was received from any organization for the submitted work. Financial relationships: All authors have declared that they have no financial relationships at present or within the previous three years with any organizations that might have an interest in the submitted work. Other relationships: All authors have declared that there are no other relationships or activities that could appear to have influenced the submitted work.

\section{References}

1. Vannata B, Stathis A, Zucca E: Management of the marginal zone lymphomas . Cancer Treat Res. 2015, 165:227-249. 10.1007/978-3-319-13150-4 9

2. Chi PI, Pei SN, Huang TL, Huang SC, Ng HY, Lee CT: Renal MALT lymphoma associated with Waldenstrom macroglobulinemia. J Formos Med Assoc. 2014, 113:255-257. 10.1016/j.jfma.2011.02.007

3. Zinzani PL: The many faces of marginal zone lymphoma . Hematology Am Soc Hematol Educ Program. 2012, 2012:426-432.

4. Cheson BD, Friedberg JW, Kahl BS, Van der Jagt RH, Tremmel L: Bendamustine produces durable responses with an acceptable safety profile in patients with rituximab-refractory indolent non-Hodgkin lymphoma. Clin Lymphoma Myeloma Leuk. 2010, 10:452-457. 10.3816/CLML.2010.n.079

5. Kang HJ, Kim WS, Kim SJ, et al.: Phase II trial of rituximab plus CVP combination chemotherapy for advanced stage marginal zone lymphoma as a first-line therapy: consortium for improving survival of lymphoma (CISL) study. Ann Hematol. 2012, 91:543-551. 10.1007/s00277-011-1337-6

6. Zucca E, Conconi A, Martinelli G, et al.: Final results of the IELSG-19 randomized trial of mucosa-associated lymphoid tissue lymphoma: Improved event-free and progression-free survival with rituximab plus chlorambucil versus either chlorambucil or rituximab monotherapy. J Clin Oncol. 2017, 35:1905-1912.

7. Sehn LH, Chua N, Mayer J, et al.: Obinutuzumab plus bendamustine versus bendamustine monotherapy in patients with rituximab-refractory indolent non-Hodgkin lymphoma (GADOLIN): a randomised, controlled, open-label, multicentre, phase 3 trial. Lancet Oncol. 2016, 17:1081-1093. 10.1016/s1470-2045(16)30097-3

8. Noy A, de Vos S, Thieblemont C, et al.: Targeting bruton tyrosine kinase with ibrutinib in 
relapsed/refractory marginal zone lymphoma. Blood. 2017, 129:2224-2232. 10.1182/blood-2016-10-747345

9. Conconi A, Martinelli G, Lopez-Guillermo A, et al.: Clinical activity of bortezomib in relapsed/refractory MALT lymphomas: results of a phase II study of the International Extranodal Lymphoma Study Group (IELSG). Ann Oncol. 2011, 22:689-695. 10.1093/annonc/mdq416

10. de Vos S, Goy A, Dakhil SR, et al.: Multicenter randomized phase II study of weekly or twice-weekly bortezomib plus rituximab in patients with relapsed or refractory follicular or marginal-zone B-cell lymphoma. J Clin Oncol. 2009, 27:5023-5030.

11. Kiesewetter B, Willenbacher E, Willenbacher W, et al.: A phase 2 study of rituximab plus lenalidomide for mucosa-associated lymphoid tissue lymphoma. Blood. 2017, 129:383-385. 10.1182/blood-2016-06-720599

12. Copanlisib and rituximab in marginal zone lymphoma patients . (2018). Accessed: May 15, 2018 : https://clinicaltrials.gov/ct2/show/record/NCT03474744? term=Copanlisib \&cond=Marginal+Zone+Lymphoma \&rank=1\&view=record.

13. Efficacy and safety study of idelalisib in subjects with indolent B-cell non-Hodgkin lymphoma (DELTA) . (2018). Accessed: June 1, 2018: https://clinicaltrials.gov/ct2/show/record/NCT01282424? term=idelalisib \& cond=Marginal+Zone+Lymphoma \&rank=2.

14. Evaluation of atezolizumab-venetoclax-obinutuzumab combination in relapse/refractory lymphomas . (2018). Accessed: May 25, 2018: https://clinicaltrials.gov/ct2/show/record/NCT03276468? term=Venetoclax \&cond=Marginal+Zone+Lymphoma \&rank=1.

15. Study of BKM120 \& rituximab in patients with relapsed or refractory indolent B-cell lymphoma . (2017). Accessed: May 14, 2018: https://clinicaltrials.gov/ct2/show/record/NCT02049541? term=Buparlisib \&cond=Marginal+Zone+Lymphoma \&rank=1.

16. A study of duvelisib in combination with rituximab and bendamustine vs placebo in combination with rituximab and bendamustine in subjects with previously-treated indolent non-Hodgkin lymphoma (BRAVURA). (2017). Accessed: May 20, 2018: https://clinicaltrials.gov/ct2/show/record/NCT02576275? term=Duvelisib \&cond=Marginal+Zone+Lymphoma \&rank=1

17. Study of ibrutinib in combination with rituximab and lenalidomide in previously untreated subjects with follicular lymphoma and marginal zone lymphoma. (2018). Accessed: May 25, 2018: https://clinicaltrials.gov/ct2/show/record/NCT02532257? term=lenalidomide \&cond=Marginal+Zone+Lymphoma\&rank=2.

18. Study to assess the efficacy and safety of umbralisib in patients with non-follicular indolent non-Hodgkin's lymphoma. (2017). Accessed: May 24, 2018: https://clinicaltrials.gov/ct2/show/record/NCT03364231? term=umbralisib \&cond=Marginal+Zone+Lymphoma \&rank=1.

19. Vorinostat in treating patients with low-grade non-Hodgkin's lymphoma . (2018). Accessed: May 16, 2018: https://clinicaltrials.gov/ct2/show/results/NCT00253630? term=Vorinostat \&cond=Marginal+Zone+Lymphoma\&rank=4.

20. Nastoupil L, Lunning M, Vose J, et al.: Chemo-free triplet combination of TGR-1202, ublituximab, and ibrutinib is well tolerated and highly active in patients with advanced CLL and NHL. Hematol Oncol. 2017, 35:112-113. 10.1002/hon.2437_101 